\title{
Low-Frequency Modulation of Intraseasonal Equatorial Kelvin Wave Activity in the Pacific from SODA: 1958-2001
}

\author{
BORIS DEWITTE \\ IRD/LEGOS, Toulouse, France, and IMARPE, Callao, Peru \\ SARA PURCA \\ IMARPE, Callao, Peru \\ SERENA ILLiG \\ IRD/LEGOS, Toulouse, France, and JPL, Pasadena, California \\ LIONEL RENAULT \\ IRD/LEGOS, Toulouse, France \\ BENJAMin S. Giese \\ Texas A\&M University, College Station, Texas
}

(Manuscript received 11 October 2007, in final form 21 March 2008)

\begin{abstract}
Intraseasonal equatorial Kelvin wave activity (IEKW) at a low frequency in the Pacific is investigated using the Simple Ocean Data Assimilation (SODA) oceanic reanalyses. A vertical and horizontal mode decomposition of SODA variability allows estimation of the Kelvin wave amplitude according to the most energetic baroclinic modes. A wavenumber-frequency analysis is then performed on the time series to derive indices of modulation of the IEKW at various frequency bands. The results indicate that the IEKW activity undergoes a significant modulation that projects onto baroclinic modes and is not related in a straightforward manner to the low-frequency climate variability in the Pacific. Linear model experiments corroborate that part of the modulation of the IEKW is tightly linked to change in oceanic mean state rather than to the low-frequency change of atmospheric equatorial variability.
\end{abstract}

\section{Introduction}

Basin-scale equatorial Pacific variability is dominated by oceanic Kelvin waves at a variety of time scales. At low frequencies (interannual time scale), the equatorial Kevin wave (EKW) has been well documented in the literature, which brought meaningful material for the understanding of the mechanisms associated to El Niño-Southern Oscillation (ENSO). On the other hand, the role of the EKW at an intraseasonal time scale (IEKW) on the coupled tropical

Corresponding author address: Boris Dewitte, IRD/LEGOS, 14 av. Edouard Belin, Toulouse 31400, France.

E-mail: bxd@imarpe.gob.pe
Pacific system remains unclear. It has been suggested that the IEKW is instrumental in the development of El Niño (Hendon et al. 1999; Kessler and Kleeman 2000; Roundy and Kiladis 2006). As a matter of fact, the stochastic forcing (in the sense that the decorrelation times of the IEKW are much smaller than the time scales associated with ENSO) has proven to be a possible explanation for several observed characteristics of ENSO, such as its predictability (Kleeman and Moore 1997; Zavala-Garay et al. 2004), irregularity (Blanke et al. 1997; Roulston and Neelin 2000), and decadal variability (Moore and Kleeman 1999). An important component of the stochastic forcing in the tropics is the Madden-Julian oscillation (MJO; Madden and Julian 1994) and associated EKW (Hendon et al. 1998). Be- 
cause of the observed seasonal dependency of the MJO-ENSO relationship (Hendon et al. 2007), a change in ENSO is likely to be associated with a change in IEKW. However, the specific connection between the MJO and ENSO at low frequency is a topic of current debate (Zavala-Garay et al. 2005).

Recent studies suggest that ENSO has experienced changes in characteristics in the last few decades (An 2004) with, in particular, a "shift" in the 1970s (Guilderson and Schrag 1998) associated with a change in the background stratification of the equatorial Pacific (Giese et al. 2002; Moon et al. 2004). Fluctuations of the background stratification impact the vertical structure of the EKW so that it is likely that IEKW is fully embedded in the coupled tropical Pacific system through rectification processes at various time scales. As a first step toward understanding the time-scale interactions associated with wave dynamics during ENSO, it is important to document the change in characteristics of IEKW at low frequency (i.e., the lowfrequency tail of the IEKW). This is the purpose of the present study.

Because the subsurface is not sampled well enough to derive vertical mode variability, the "one mode" approximation (which assumes that the mean stratification can be accounted by the single gravest baroclinic mode) has been used successfully with altimetric data (Delcroix et al. 1994; Dewitte and Périgaud 1996; Boulanger and Fu 1996; Delcroix et al. 2000) to determine the EKW amplitude. Although there are limitations linked to the use of a biased model and assimilation scheme, Dewitte et al. (2003) show that for the tropical Pacific assimilation products can bring further insight to the interpretation of altimetric data and surface variability associated to equatorial waves. In particular, for the 1997/98 El Niño event, second-baroclinic-mode EKWs are shown to be as energetic as first-mode EKWs, with characteristics evolving differently as El Niño develops. Cravatte et al. (2003) also show from the output of a forced ocean general circulation model (OGCM) that $\sim 120$-day variability projects onto the second baroclinic mode, whereas 70-day EKW variability is more energetic for the first mode.

In this study, following Dewitte et al. (2003), we take advantage of an extensively used long-term assimilation experiment for the global ocean, the SODA ocean reanalysis (Carton and Giese 2008), to investigate EKW variability according to the most energetic baroclinic modes. The extended period of SODA allows us to focus on slowly evolving variability of the IEKW.

This paper is structured as follows: we first briefly present the datasets and the method to derive wave coefficients (section 2). Section 3 is devoted to the analysis of the results and section 4 contains a discussion followed by concluding remarks.

\section{Datasets and SODA description and method}

\section{a. Data}

Satellite-derived observations are used in this study to estimate the realism of SODA. Sea level height (SL) anomalies are obtained from Ocean Topography Experiment (TOPEX)/Poseidon and European Remote Sensing Satellite (ERS)-1/2 datasets from October 1992 to December 2001. The SL global maps result from an optimal interpolation of combined altimetry data on the Mercator $1 / 3^{\circ}$ grid every week. SL anomalies are computed with respect to the 7-yr mean from January 1993 to January 1999. A detailed description of this combined altimetric product is given by Ducet et al. (2000; available online at http://www.aviso.oceanobs. com).

Near-surface currents were obtained from the ocean surface current analysis product, Ocean Surface Current Analyses-Real Time (OSCAR), derived from a satellite altimeter, scatterometer, and sea surface temperature (SST; Bonjean and Lagerloef 2002). The surface layer current is the sum of geostrophic and Ekman currents and of a buoyancy term. The Reynolds SST dataset (Reynolds and Smith 1994) is used to estimate the Pacific decadal index.

\section{b. $S O D A$}

The SODA reanalysis project, which began in the mid-1990s, is an ongoing effort to reconstruct historical ocean climate variability on space and time scales similar to those captured by the atmospheric reanalysis projects. In this paper, we used the SODA version 1.4.2. SODA 1.4.2 uses a general circulation ocean model based on the Parallel Ocean Program numerics (Smith et al. 1992), with an average $0.25^{\circ}$ latitude $\times 0.4^{\circ}$ longitude horizontal resolution and 40 vertical levels with $10-\mathrm{m}$ spacing near the surface. The constraint algorithm is based on optimal interpolation data assimilation. Assimilated data include temperature and salinity profiles from the World Ocean Atlas 2001 [mechanical bathythermograph (MBT), XBT, CTD, and station data; Conkright et al. 2002], as well as additional hydrography, SST, and altimeter sea level. The model was forced by daily surface winds provided by the 40-yr European Centre for Medium-Range Weather Forecasts (ECMWF) Re-Analysis (ERA-40; Uppala et al. 2005) for the 44-yr period from January 1958 to 


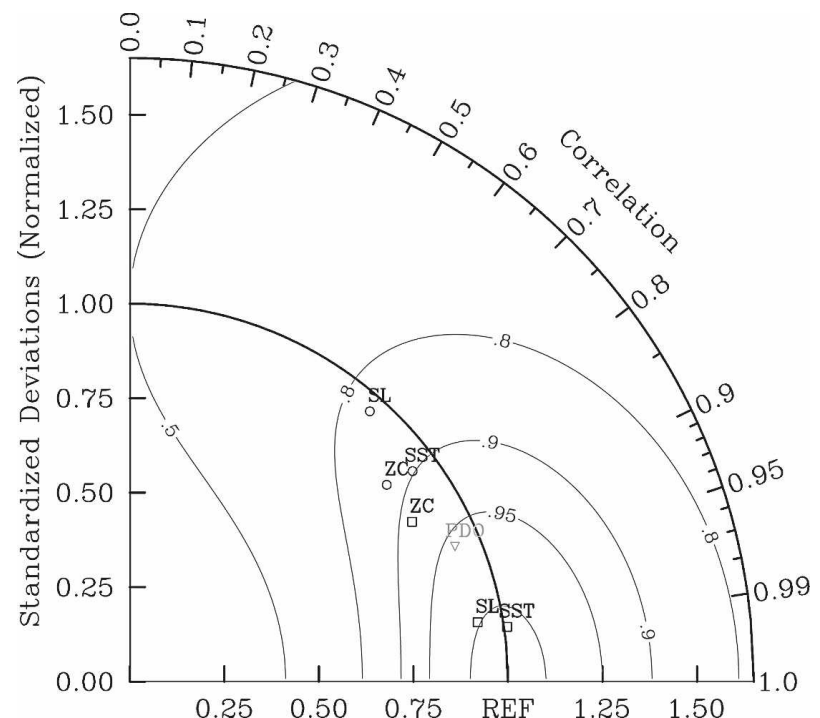

FIG. 1. Taylor diagram illustrating the SODA reanalysis skill over the 1992-2001 period. Second-order statistics of surface zonal current $\left[\mathrm{ZC}\right.$; averaged over Niño-4 $\left(5^{\circ} \mathrm{S}-5^{\circ} \mathrm{N}, 150^{\circ} \mathrm{E}-\right.$ $\left.150^{\circ} \mathrm{W}\right)$ ], sea level height [SL averaged over Niño-3 $\left(5^{\circ} \mathrm{S}-5^{\circ} \mathrm{N}\right.$, $\left.150^{\circ} \mathrm{W}-90^{\circ}\right)$ ], and sea surface temperature (SST averaged over Niño-3) anomalies by SODA for the intraseasonal $\left(f_{c}=150\right.$ $\mathrm{day}^{-1}$, circle symbols) and interannual (square symbols) variability. Gray isolines provide a measure of skill, as defined by Eq. (4) in Taylor (2001). The radial coordinate gives the magnitude of total standard deviation, normalized by the observed value, and the angular coordinate gives the correlation with observations. It follows that the distance between the observed point and any model's point is proportional to the RMS model error. The observations (REF) are the merged altimetric SL product, the satellite-derived surface currents (OSCAR product), and the Reynolds SST. As an indication, the Pacific decadal oscillation (PDO; triangle) is also displayed in the diagram. The PDO indices are derived from the leading EOF of monthly SSTA $\left(20^{\circ}-60^{\circ} \mathrm{N}\right.$, $\left.110^{\circ} \mathrm{E}-110^{\circ} \mathrm{W}\right)$. The global average anomaly has been subtracted to account for global warming (Hare and Mantua 2000).

December 2001. Surface freshwater flux for the period of 1979-present are provided by the Global Precipitation Climatology Project monthly satellite-gauge merged products (Adler et al. 2003) combined with evaporation obtained from the same bulk formula used to calculate latent heat loss. Sea level is calculated prognostically using a linearized continuity equation, which is valid for small ratios of sea level to fluid depth (Dukowicz and Smith 1994). The reader is invited to refer to Carton et al. (2000) and Carton and Giese (2008) for a detailed description of the SODA system.

As an indication of the realism of the SODA reanalysis, Fig. 1 provides a Taylor diagram (Taylor 2001), which includes various indices, the most relevant of which for the present study are the ones associated with zonal current and sea level anomalies because we use both fields to derive the contribution of the Kelvin wave (cf. below). In this polar plot, the azimuthal angle provides a measure of the correlation $(R)$ between the model and observations. The radial distance from the origin $(r)$ to any point is the ratio of the model RMS to that of the observations. The latter is located at $[R=1$; $r=1]$, and is marked as "REF." The distance from any point to REF is equal to the normalized error (ratio of the RMS difference between model and observations to the RMS of the observations). Figure 1 indicates that over the 1992-2001 period SODA agrees well with the observations at both interannual and intraseasonal time scales, also having slightly less energy than the observations.

In the rest of the study, we will analyze the 1958-2001 period of SODA.

\section{c. Method}

To infer the Kelvin wave amplitude, a vertical mode decomposition of SODA mean equatorial stratification is first carried out to derive baroclinic mode contributions to pressure and zonal current anomalies. To acquire the low-frequency changes in the mean stratification, the vertical mode decomposition is performed at each time step using varying salinity and temperature profiles from SODA. The latter's are obtained by adding to the mean (1958-2001) the low-frequency variability of the stratification obtained by low-pass filtering SODA temperature and salinity fields $\left(f_{c}=7 \mathrm{yr}^{-1}\right)$. Projecting the results onto the theoretical Kelvin and Rossby wave structures provides an estimation of the equatorial wave amplitude. This method was used successfully in previous studies for the equatorial Pacific (Dewitte el al. 1999, 2003) and Atlantic (Illig et al. 2004).

Consistent with the results of Dewitte et al. (2003), the most energetic Kelvin waves are found to be for the first three baroclinic modes. The first three baroclinic modes explain up to $60 \%$ of the total explained variance along the equator (Fig. 2a). The first baroclinic mode is dominant in the western-central Pacific whereas mode 2 peaks in the eastern Pacific, which is due to the difference in mean thermocline depth and stratification between the east and west (cf. Dewitte et al. 1999). Growth of the second baroclinic mode relative to the first baroclinic mode as Kelvin waves propagate into the eastern Pacific is also consistent with the theoretical predictions of Giese and Harrison (1990). At frequencies higher than 6 month $^{-1}$ (Fig. 2b), the energy distribution of each baroclinic mode along the equator is comparable to that of the interannual anomalies (Fig. 2a). 

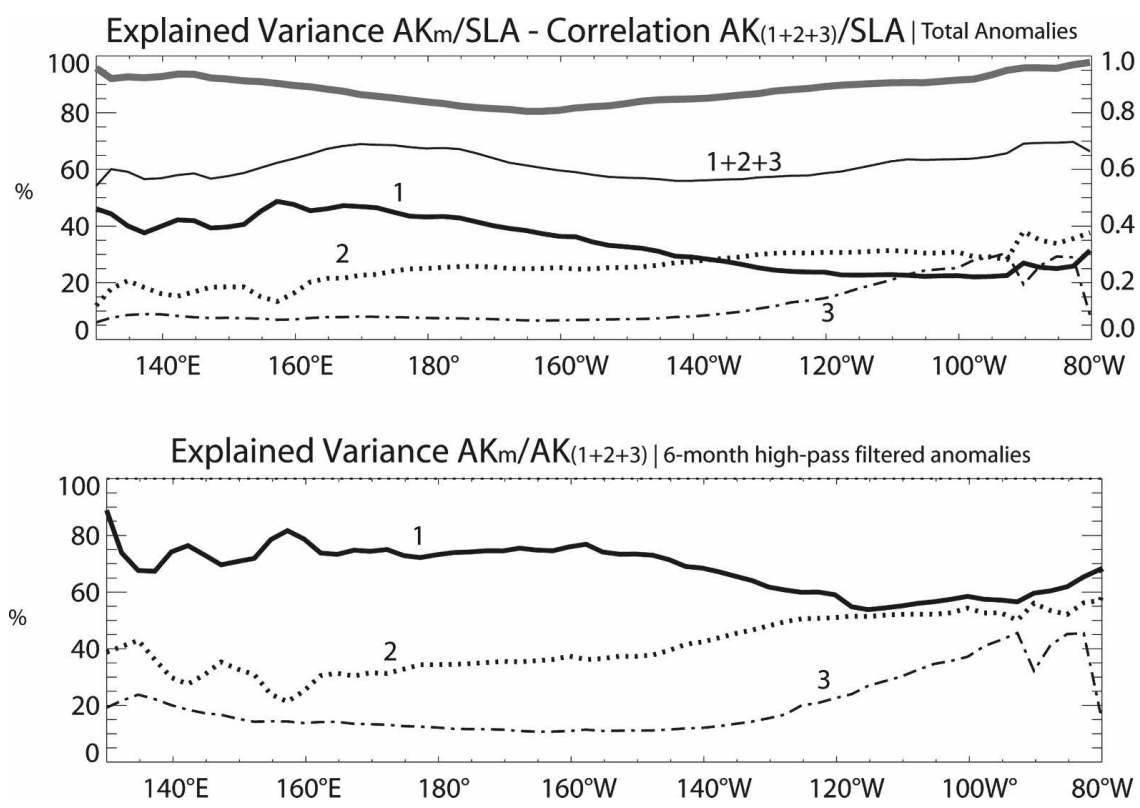

FIG. 2. (top) Explained variance of the first (thick full line), second (thick dotted line), and third (dotted-dashed line) baroclinic modes and the summed contribution of the first three baroclinic modes (thin full line) with respect to the total sea level anomalies (left scale). The correlation between the contribution of the summed-up contribution of modes 1-3 and the total SLA is indicated by a thick gray line (right scale). (bottom) Explained variance of the first (thick full line), second (thick dotted line), third (dotted-dashed line) baroclinic modes with respect to the summed contribution of modes 1-3 for the 6-month high-pass-filtered time series.

\section{Results}

\section{a. Low-frequency modulation of the IEKW}

The time series of the EKW amplitude derived from the vertical mode decomposition of SODA are first investigated using a wavelet analysis. The wavelet power of the series in the western-central and eastern equatorial Pacific reveals a rich spectrum of variability in the intraseasonal band (Fig. 3b). In particular, the level of energy in the intraseasonal band (10-140 days) is comparable to that in the interannual band (2-7 yr). Two frequency bands are extracted by averaging the wavelet power (Figs. 3c,d). There are the following three results: 1) there is a low-frequency modulation of highfrequency variability; 2) this modulation is not related in a straightforward manner to ENSO activity and modulation as measured by the scale-averaged wavelet power over the [2-7]-yr band (cf. Fig. 3a); and 3) for a particular frequency band (hereafter referred to as the N3VAR index), the first- and second-baroclinic-mode IEKW activities are not necessarily correlated.

\section{b. Definition of indices of IEKW activity}

To analyze the propagating nature of the estimated EKW, a bivariate space-time spectral analysis (Hayashi
$1982)$ is applied on the high-pass- $\left(f_{c}=1 \mathrm{yr}^{-1}\right)$ filtered outputs along the equator for the first three energetic baroclinic modes. Results are displayed in Fig. 4 for the first two baroclinic modes and for two different periods known to be characterized by different properties of ENSO variability (An 2004). The diagrams reveal the presence of long-wavelength $(k<2)$ Kelvin wave at $\sim 10, \sim 70$, and $\sim 50 \mathrm{day}^{-1}$ for the first baroclinic mode and at $\sim 100$ and $\sim 70$ day $^{-1}$ for the second baroclinic mode. The presence of dominant EKW at $\sim 70$ day $^{-1}$ for the first baroclinic mode is consistent with the study by McPhaden and Taft (1988), and the presence of dominant EKW at $\sim 100$ day $^{-1}$ for the second baroclinic mode is consistent with the study by Cravatte et al. (2003). The theoretical dispersion curve fits with most spectral density peaks except for the $\sim 100$-day EKW of the first baroclinic mode. This is believed to be due to the modal dispersion associated with zonal and temporal changes in stratification (Busalacchi and Cane 1988; Dewitte et al. 1999). In particular, the $\sim 50$ day EKW wave may experience significant dispersion from $\sim 120^{\circ} \mathrm{W}$ (Dewitte et al. 1999), which, coupled with the deepening and shallowing of the thermocline at semiannual time scales, may produce variability at $\sim 100$ days. Interestingly, the diagram exhibits a change 

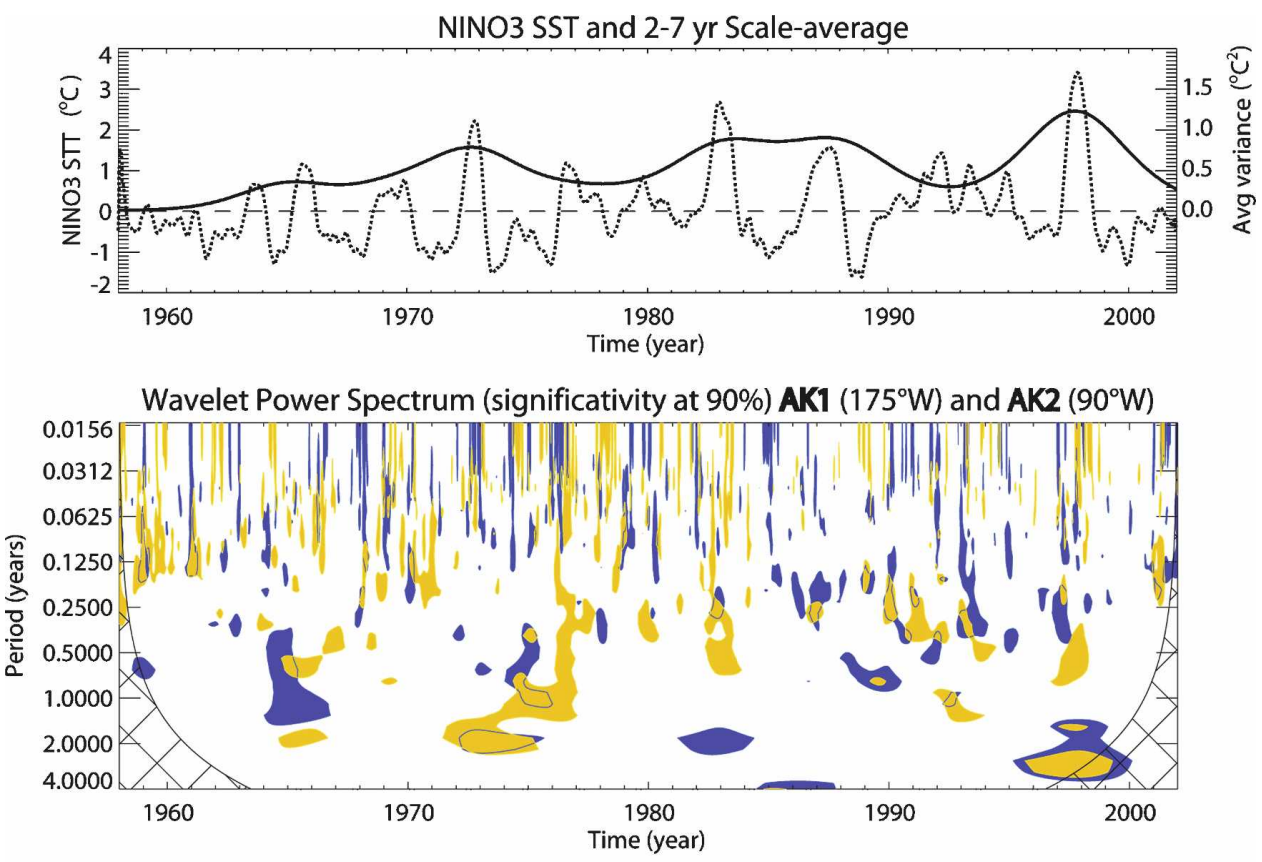

[50-80] days Scale-average Time Series

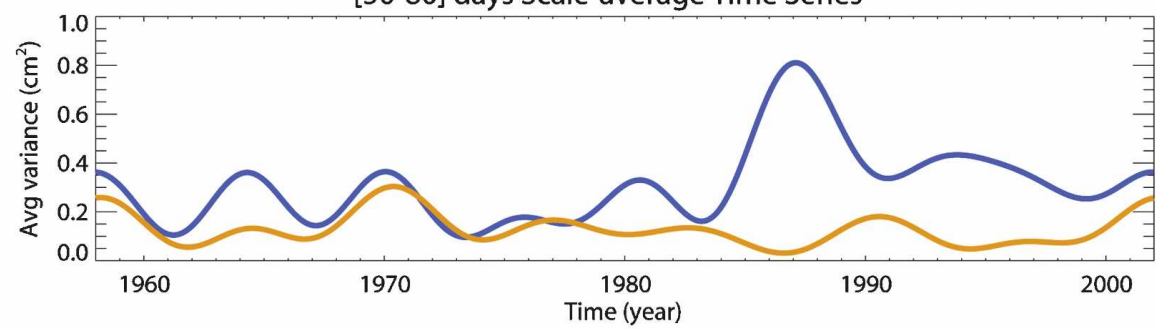

[100-140] days Scale-average Time Series

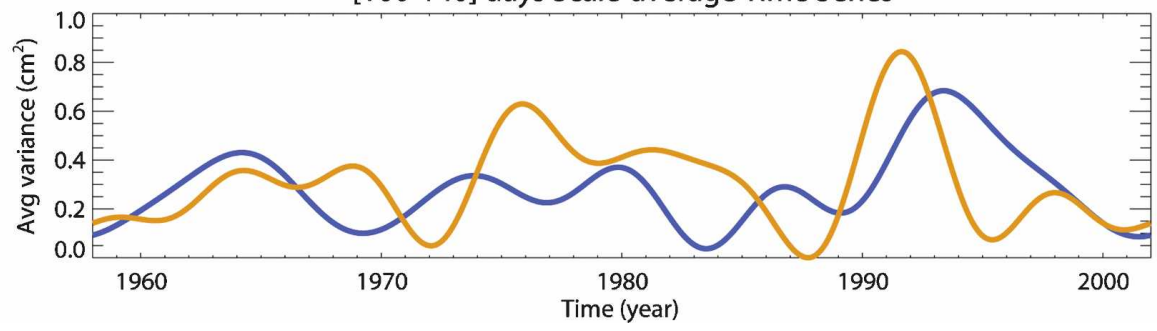

FIG. 3. (a) The Niño-3 SST index $\left({ }^{\circ} \mathrm{C}\right.$; left scale, dotted line) and associated scale-averaged wavelet power over the [2-7] yr (full line) from SODA. (b) The wavelet spectrum for the first- (blue) and second(orange) baroclinic-mode Kelvin wave amplitude at $175^{\circ}$ and $90^{\circ} \mathrm{W}$, respectively using the Morlet wavelet. Only values above the $95 \%$ confidence level (red noise $\alpha=0.72$ ) are displayed. (c) The scale-averaged wavelet power over the [50-80]-day band for the (blue line) first and (orange line) second baroclinic Kelvin wave contribution at $175^{\circ}$ and $90^{\circ} \mathrm{W}$, respectively. Series were 5-yr low-pass filtered to highlight the low-frequency component. (d) Same as (c), but for the [100-140]-day band.

in the intensity and location of the maximum amplitude as a function time. In the period prior to the 1976/77 climate shift, IEKW is less energetic than for the subsequent period. This suggests a low-frequency modulation of the IEKW. To quantify this modulation, the same analysis as before is performed for 6-yr running segments. This results in 2664 diagrams in which we seek the "location" of the maximum amplitude for zonal wavenumber 1 in the frequency band centered around 100,70 , and 50 days $^{-1}$. Inspection of the individual diagrams over time indicates that the IEKW centered on $\sim 100$ days $^{-1}$ experiences the largest variability 

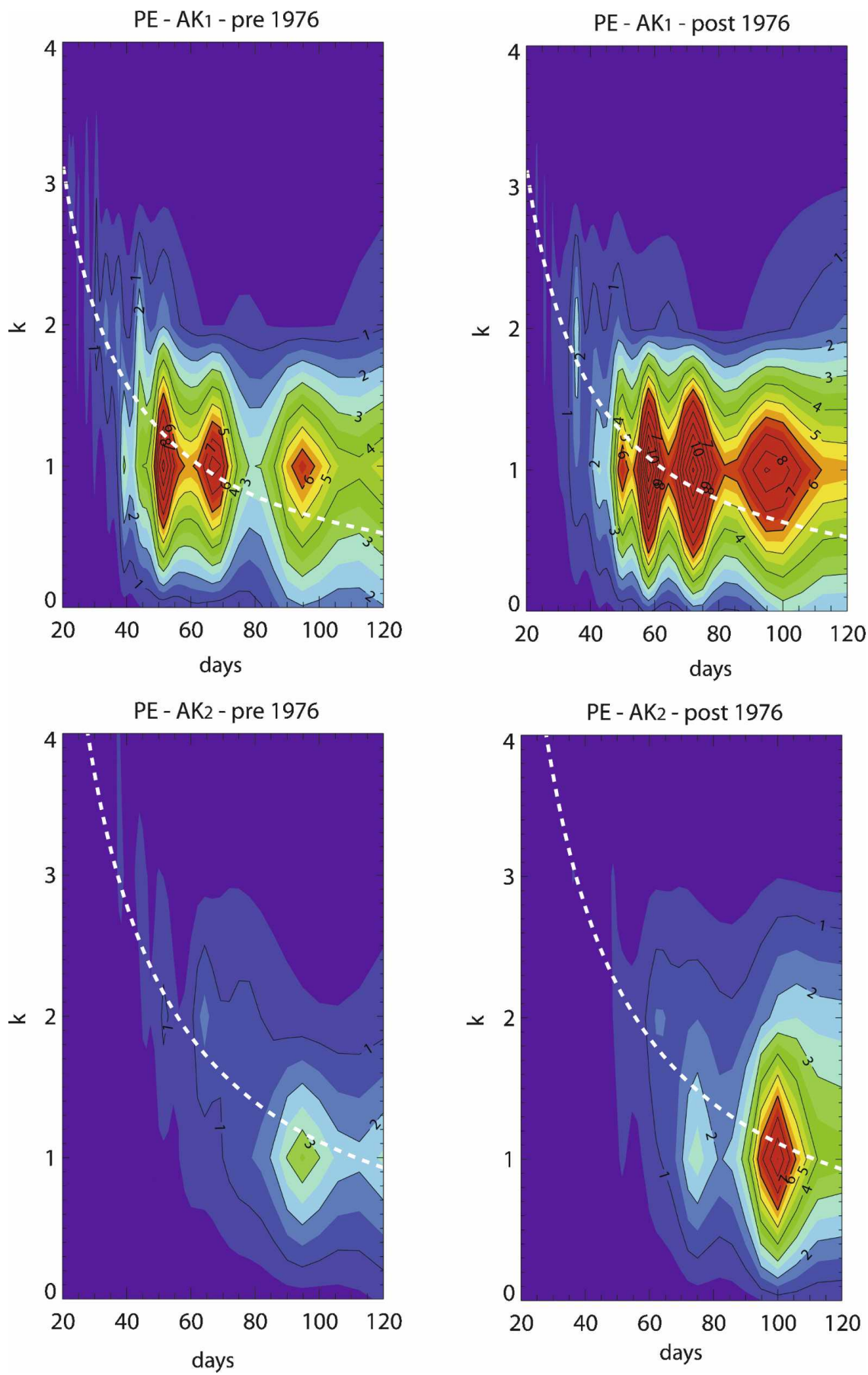

FIG. 4. The space-time power spectral density of the Kelvin (at the equator) wave for the (top) first and (bottom) second baroclinic modes for two periods: (left) 1958-75 and (right) 1977-2001. Theoretical dispersion curves for Kelvin waves using the zonally averaged phase velocity as derived from the vertical mode decomposition are plotted with a thick dotteddashed line.

in dominant frequency. The frequency bands that were chosen are then [90-120], [70-80], and [50-60] days ${ }^{-1}$. Figure 5 displays the obtained series. They exhibit a clear modulation at a low frequency with distinct char- acteristics according to the mode order and the frequency. The correlation for the 70-day EKW between the first and second baroclinic modes reaches 0.66. On the other hand, the series for the first and second mode 

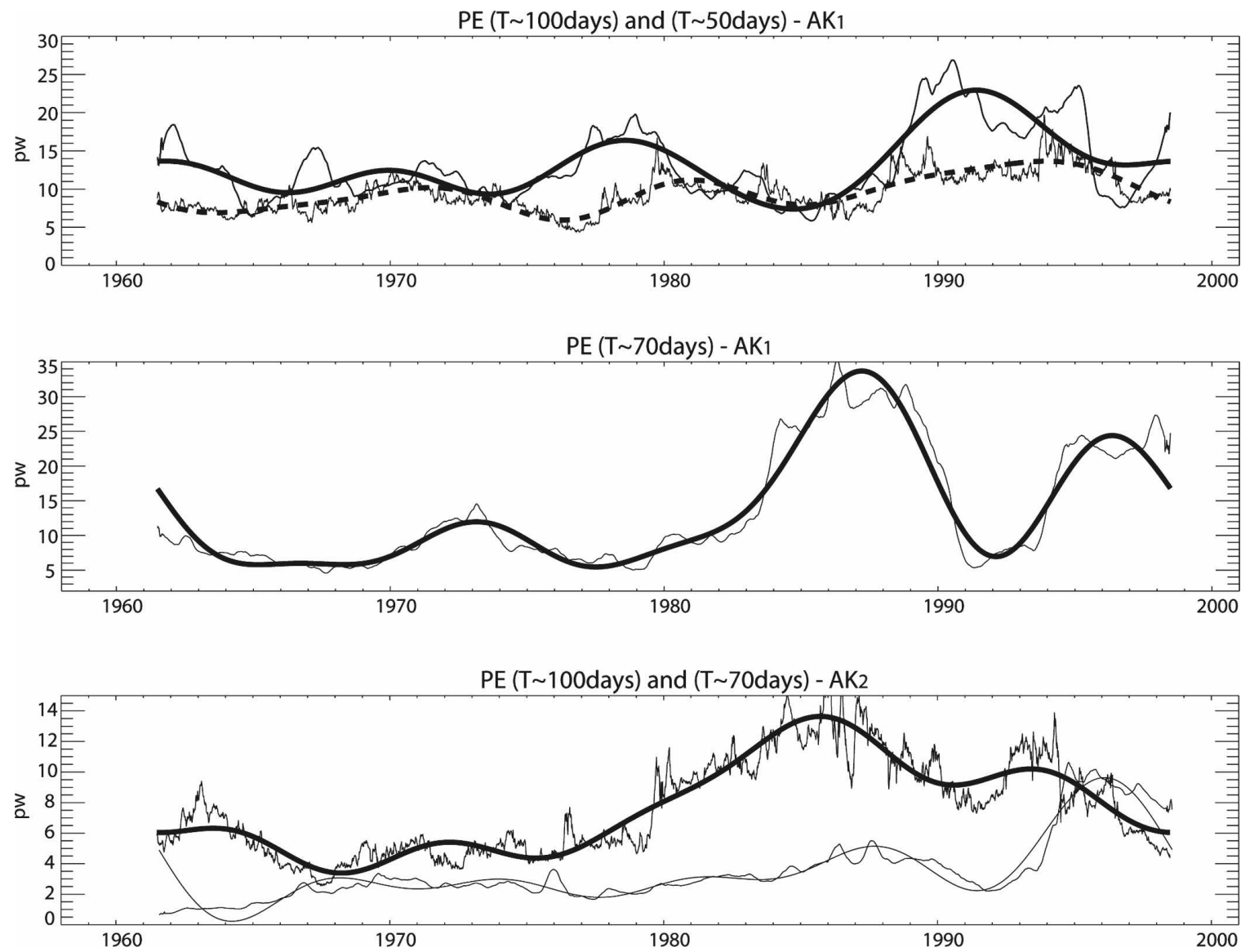

FIG. 5. Power spectral density resulting from the space-time decomposition over 6-yr time running windows for zonal wavenumber 1 at the frequencies of (top) 110 days $^{-1}$ (thick dotted line), 50 days $^{-1}$ (thick full line), and (middle) 70 days $^{-1}$ for the first-baroclinic-mode Kelvin wave, and (bottom) 120 days $^{-1}$ (thick full line) and 90 days $^{-1}$ (thin full line) for the second-baroclinicmode Kelvin wave. The 7-yr low-pass filtered is displayed above the nonfiltered time series.

at 100 day $^{-1}$ are not significantly correlated. The largest modulation amplitude is found for the first-baroclinicmode EKW at $70 \mathrm{day}^{-1}$, which is more than twice the modulation of other indices.

\section{Discussion and conclusions}

Oceanic intraseasonal variability in the equatorial Pacific is studied using the SODA 1.4.2 oceanic reanalysis from 1958 to 2001. Our focus is on the lowfrequency modulation of the "high frequency" component of EKW activity. It is shown that the IEKW undergoes significant amplitude changes at decadal time scales for the frequency bands centered around 100, 70, and 50 days $^{-1}$ for the first baroclinic mode and 100 and 70 days $^{-1}$ for the second baroclinic mode. Interestingly, the modulation has different characteristics (amplitude and phase) according to the baroclinic mode and frequency, which suggests that it does not result in a straightforward manner from decadal change in exter- nal forcing. Regarding intraseasonal atmospheric variability not as the external stochastic forcing of the ENSO cycle (Eisenman et al. 2005), the IEKW modulation might thus result from rectification processes involving the change in mean state, as for the ENSO modulation (Dewitte et al. 2007) or from change in intraseasonal atmospheric variability characteristics (Teng and Wang 2003; Jones and Carvalho 2006). To support this hypothesis, we calculated the correlation between indices of the IEKW modulation as derived from Fig. 5 and various "classical" indices relevant for the study of decadal variability in the Pacific. The first categories of indices are derived from the vertical mode decomposition of the slowly varying equatorial stratification of SODA. They correspond to the projection coefficients of wind forcing (in the linear sense) for the first three baroclinic modes and measure the change in mean thermocline characteristics [depth and intensity; the reader is invited to refer to Dewitte et al. (2007) for more details on the value of such parameters in com- 
TABLE 1. Correlation between the IEKW modulation indices and various indices of the climate variability (first six lines) and the IEKW modulation indices as derived from a linear simulation (last line; see text). Correlation values significant at the $95 \%$ level are displayed in bold.

\begin{tabular}{|c|c|c|c|c|c|}
\hline & $\mathrm{EKW}_{1}, 100$ days $^{-1}$ & $\mathrm{EKW}_{1}, 70$ days $^{-1}$ & $\mathrm{EKW}_{1}, 50$ days $^{-1}$ & $\mathrm{EKW}_{2}, 100$ days $^{-1}$ & $\mathrm{EKW}_{2}, 70$ days $^{-1}$ \\
\hline$P_{1}^{\mathrm{a}}$ & 0.69 & 0.13 & 0.72 & 0.47 & 0.30 \\
\hline$P_{2}{ }^{\mathrm{a}}$ & 0.67 & 0.38 & 0.28 & 0.76 & 0.53 \\
\hline$P_{3}^{a}$ & 0.70 & 0.10 & 0.45 & 0.52 & 0.38 \\
\hline $\mathrm{N} 3 \mathrm{VAR}^{\mathrm{b}}$ & 0.18 & 0.73 & -0.33 & 0.42 & 0.58 \\
\hline SVD1-TXlpf ${ }^{\mathrm{c}}$ & 0.20 & -0.37 & 0.21 & -0.25 & -0.12 \\
\hline $\mathrm{PDO}^{\mathrm{d}}$ & 0.44 & 0.63 & 0.10 & 0.79 & 0.57 \\
\hline $\mathrm{LODCA}^{\mathrm{e}}$ & 0.08 & 0.88 & 0.91 & 0.39 & 0.51 \\
\hline
\end{tabular}

${ }^{a}$ Wind projection coefficients for the first three baroclinic modes as derived from the vertical mode decomposition of the slowly varying stratification.

${ }^{\text {b }}$ Scale-averaged wavelet power over the 2-7 yr of the Niño-3 SST index (ENSO modulation indices; cf. Cibot et al. 2005).

${ }^{\mathrm{c}}$ First SVD mode between 7-yr low-pass-filtered SST and wind stress anomalies.

${ }^{\mathrm{d}}$ Pacific Decadal Oscillation index (7-yr low-pass filtered).

e IEKW modulation indices as derived from a linear model (Dewitte 2000) forced with the ERA-40 winds.

parison with just the change in thermocline depth to diagnose the decadal mode along the equator]. ENSO modulation is diagnosed using the scale-averaged wavelet power of the Niño-3 SST index over the [2-7]-yr band (N3VAR index), whereas the tropical decadal mode is derived from the singular value decomposition (SVD) between 7-yr low-pass-filtered wind stress and SST anomalies in the equatorial Pacific $\left(11^{\circ} \mathrm{S}-11^{\circ} \mathrm{N}\right)$. Last, the PDO index is calculated from SODA SST following Hare and Mantua (2000), and the results are summarized in Table 1.

Interestingly, the IEKW modulation indices do not exhibit a clear phase relationship with the indices of the tropical Pacific low-frequency variability (viz., with N3VAR and SVD1-TXlpf). Only the 70-day IEKW exhibits a significant correlation with the N3VAR index, suggesting that it is related to ENSO modulation and is consistent with the MJO linkage to ENSO (Hendon et al. 2007) and the frequency spreading process noted by Roundy and Kiladis (2006). The PDO index correlates well with the second-baroclinic-mode Kelvin wave but not with first-baroclinic-mode Kelvin wave. Only the 70-day IEKW of the first baroclinic mode exhibits a significant correlation with the PDO. For the indices of mean stratification change $\left(P_{n}\right)$, a relatively high correlation between $P_{n}$ and the EKW at $100 \mathrm{day}^{-1}$ for the first and second modes is observed. The 50-day EKW of the first baroclinic mode and the 70-day EKW of the second baroclinic mode also exhibit a significant correlation with $P_{1}$ and $P_{2}$, respectively. This suggests that modulation of the IEKWs is related to change in the ocean mean state. Overall, the results of Table 1 illustrate the complex nature of the processes involved in the forcing of the IEKW. For instance, nonlinear coupling between the atmospheric forcing and surface oceanic circulation has been invoked to explain the differing frequency between the MJO and Kelvin waves (Lau and Shen 1988; Bergman et al. 2001; Shinoda and Hendon 2002; Roundy and Kiladis 2006). To assess the "direct" impact of wind forcing on our results, a linear model is forced using the ERA-40 winds and similar wavenumber-frequency analyses were performed from the model outputs. The linear model is the same as that used by Dewitte (2000), but is tuned with the wind projection coefficients and the values for phase speed as derived from the vertical mode decomposition of the mean SODA stratification at $160^{\circ} \mathrm{W}$ along the equator $\left(P_{1}=0.61, P_{2}=0.51, P_{3}=0.16, c_{1}=2.67\right.$ $\left.\mathrm{m} \mathrm{s}^{-1}, c_{2}=1.58 \mathrm{~m} \mathrm{~s}^{-1}, c_{3}=1.00 \mathrm{~m} \mathrm{~s}^{-1}\right)$. Note that the linear model simulates a Niño-3 SST index that correlates with SODA, with a value for correlation of 0.81 . The correlation between the linear model and SODA for the IEKW modulation indices are reported in Table 1. Although there are limitations because of the simplicity of the linear model (mostly a tendency to overestimate the reflections at the meridional boundaries and the simplified formulation for friction used to model the dissipation of the waves), the results indicate that wind forcing can explain the modulation of the 50- and 70-day EKW activity of the first baroclinic mode and too a lesser extent the one of the 70-day EKW of the second baroclinic mode. However, it cannot explain the modulation of the 100-day EKW. Because the linear model does not have thermocline dynamics (i.e., it cannot account for the change in $P_{n}$, e.g.), the modulation of the 100-day EKW has to results from change in mean state. This is consistent with the significantly high values for correlation between the modulation of the $P_{n}$ and the 100-day EKW modulation index (cf. Table 1). 
The results presented here are critically dependent on how the atmospheric reanalysis reproduces intraseasonal variability in the equatorial Pacific. One concern is whether atmospheric reanalyses can reproduce the low-frequency modulation of the intraseasonal variability considering the nonhomogeneous datasets that are assimilated. Recent studies suggest that a change in wind forcing at these frequencies is not obviously related to increases in observational samplings resulting from satellite-derived winds assimilated in the atmospheric models. For instance, Jones and Carvalho (2006), using MJO events throughout the entire year in the National Centers for Environmental PredictionNational Center for Atmospheric Research (NECPNCAR) reanalysis (1958-2004), show that the MJO exhibits a steady increase from the early 1960s to early 1970s, and a steady decrease in activity up to the mid1980 s, followed by increases until the late 1990s. Considering that MJO activity (at a period centered around 40-50 days) is associated with Kelvin waves at 70 days (McPhaden and Taft 1988), this is consistent with our results (Fig. 5b).

Overall our study provides background material for a consistency check of the realism of reanalysis products for the intraseasonal band over an extended period of time. Another motivation for this study was to provide a description of the IEKW activity at decadal time scale that could be used for the study of the coastal variability along the coast of Peru-Chile that behaves as an extension of the equatorial waveguide. This is the topic of ongoing research.

Acknowledgments. The two anonymous reviewers are thanked for their constructive comments that allowed improving the manuscript.

\section{REFERENCES}

Adler, R. F., and Coauthors, 2003: The version-2 Global Precipitation Climatology Project (GPCP) monthly precipitation analysis (1979-present). J. Hydrometeor., 4, 1147-1167.

An, S. I., 2004: Interdecadal changes in the El Niño-La Niña asymmetry. Geophys. Res. Lett., 31, L23210, doi:10.1029/ 2004GL021699.

Bergman, J. W., H. H. Hendon, and K. M. Weickmann, 2001: Intraseasonal air-sea interactions at the onset of El Niño. J. Climate, 14, 1702-1718.

Blanke, B., J. D. Neelin, and D. Gutzler, 1997: Estimating the effect of stochastic wind stress forcing on ENSO irregularity. J. Climate, 10, 1473-1486.

Bonjean, F., and G. S. E. Lagerloef, 2002: Diagnostic model and analysis of the surface currents in the tropical Pacific Ocean. J. Phys. Oceanogr., 32, 2938-2954.

Boulanger, J. P., and L.-L. Fu, 1996: Evidence of boundary reflection of Kelvin and first-mode Rossby waves from TOPEX Poseidon sea level data. J. Geophys. Res., 101, 16 361-16 371.
Busalacchi, A. J., and M. A. Cane, 1988: The effect of varying stratification on low-frequency equatorial motions. J. Phys. Oceanogr., 18, 801-812.

Carton, J. A., and B. S. Giese, 2008: A reanalysis of ocean climate using Simple Ocean Data Assimilation (SODA). Mon. Wea. Rev., 136, 2999-3017.

, G. Chepurin, and X. Cao, 2000: A simple ocean data assimilation analysis of the global upper ocean 1950-95. Part I: Methodology. J. Phys. Oceanogr., 30, 294-309.

Cibot, C., E. Maisonnave, L. Terray, and B. Dewitte, 2005: Mechanisms of tropical Pacific interannual-to-decadal variability in the ARPEGE/ORCA global coupled model. Climate Dyn., 24, 823-842, doi:10.1007/s00382-004-0513-y.

Conkright, M. E., R. A. Locarnini, H. E. Garcia, T. D. O'Brien, T. P. Boyer, C. Stephens, and J. I. Antonov, 2002: Objective analyses, data statistics, and figures: CD-ROM documentation. World Ocean Atlas 2001, NOAA, 17 pp.

Cravatte, S., J. Picaut, and G. Eldin, 2003: First and second baroclinic Kelvin modes in the equatorial Pacific at intraseasonal timescales. J. Geophys. Res., 108, 3266, doi:10.1029/ 2002JC001511.

Delcroix, T., J. P. Boulanger, F. Masia, and C. Menkes, 1994: GEOSAT-derived sea level and surface current anomalies in the equatorial Pacific during the 1986-1989 El Niño and La Niña. J. Geophys. Res., 99, 25 093-25 107.

—, B. Dewitte, Y. duPenhoat, F. Masia, and J. Picaut, 2000: Equatorial waves and warm pool displacements during the 1992-1998 El Niño Southern Oscillation events: Observation and modelling. J. Geophys. Res., 105, 26 045-26 062.

Dewitte, B., 2000: Sensitivity of an intermediate coupled oceanatmosphere model of the tropical Pacific to its oceanic vertical structure. J. Climate, 13, 2363-2388.

_ and C. Périgaud, 1996: El Niño-La Niña events simulated with Cane and Zebiak's model and observed with satellite or in situ data. Part II: Model forced with observations. J. Climate, 9, 1188-1207.

_ , G. Reverdin, and C. Maes, 1999: Vertical structure of an OGCM simulation of the equatorial Pacific Ocean in 19851994. J. Phys. Oceanogr., 29, 1542-1570.

— S. Illig, L. Parent, Y. duPenhoat, L. Gourdeau, and J. Verron, 2003: Tropical Pacific baroclinic mode contribution and associated long waves for the 1994-1999 period from an assimilation experiment with altimetric data. J. Geophys. Res., 108, 3121, doi:10.1029/2002JC001362.

, S.-W. Yeh, B.-K. Moon, C. Cibot, and L. Terray, 2007: Rectification of the ENSO variability by interdecadal changes in the equatorial background mean state in a CGCM simulation. J. Climate, 20, 2002-2021.

Ducet, N., P. Le Traon, and G. Reverdin, 2000: Global high resolution mapping of ocean circulation from TOPEX/Poseidon and ERS-1/2. J. Geophys. Res., 105, 19 477-19 498.

Dukowicz, J., and R. D. Smith, 1994: Implicit free-surface method for the Bryan-Cox-Semtner ocean model. J. Geophys. Res., 99, 7991-8014.

Eisenman, I., L. Yu, and E. Tziperman, 2005: Westerly wind bursts: ENSO's tail rather than the dog? J. Climate, 18, 52245238.

Giese, B. S., and D. E. Harrison, 1990: Aspects of the Kelvin wave response to episodic wind forcing. J. Geophys. Res., 95, 72897312.

- S. C. Urizar, and N. S. Fučkar, 2002: Southern Hemisphere origins of the 1976 climate shift. Geophys. Res. Lett., 29, 1014, doi:10.1029/2001GL013268. 
Guilderson, T. P., and D. P. Schrag, 1998: Abrupt shift in subsurface temperatures in the tropical Pacific associated changes in El Niño. Science, 281, 240-243.

Hare, S. R., and N. J. Mantua, 2000: Empirical evidence for North Pacific regime shifts in 1977 and 1989. Prog. Oceanogr., 47 (2-4), 103-146.

Hayashi, Y., 1982: Space-time spectral analysis and its applications to atmospheric waves. J. Meteor. Soc. Japan, 60, 156171.

Hendon, H. H., B. Liebmann, and J. D. Glick, 1998: Oceanic Kelvin waves and the Madden-Julian oscillation. J. Atmos. Sci., 55, 88-101.

,-- , and -1999 : Interannual variability of the MaddenJulian oscillation during austral summer. J. Climate, 12, 25382550.

- M. C. Wheeler, and C. Zhang, 2007: Seasonal dependence of the MJO-ENSO relationship. J. Climate, 20, 531-543.

Illig, S., B. Dewitte, N. Ayoub, Y. du Penhoat, G. Reverdin, P. De Mey, F. Bonjean, and G. S. E. Lagerloef, 2004: Interannual long equatorial waves in the tropical Atlantic from a high-resolution ocean general circulation model experiment in 1981-2000. J. Geophys. Res., 109, C02022, doi:10.1029/ 2003JC001771.

Jones, C., and L. M. V. Carvalho, 2006: Changes in the activity of the Madden-Julian oscillation during 1958-2004. J. Climate, 19, 6353-6370.

Kessler, W. S., and R. Kleeman, 2000: Rectification of the Madden-Julian oscillation into the ENSO cycle. J. Climate, 13, $3560-3575$

Kleeman, R., and A. M. Moore, 1997: A theory for the limitations of ENSO predictability due to stochastic atmospheric transients. J. Atmos. Sci., 54, 753-767.

Lau, K.-M., and S. Shen, 1988: On the dynamics of intraseasonal oscillations and ENSO. J. Atmos. Sci., 45, 1781-1797.

Madden, R. A., and P. R. Julian, 1994: Observations of the 4050-day tropical oscillation-A review. Mon. Wea. Rev., 122, 814-837.

McPhaden, M. J., and B. A. Taft, 1988: On the dynamics of sea- sonal and intraseasonal variability in the eastern equatorial Pacific. J. Phys. Oceanogr., 18, 1713-1732.

Moon, B.-K., S.-W. Yeh, B. Dewitte, J.-G. Jhun, I.-S. Kang, and B. P. Kirtman, 2004: Vertical structure variability in the equatorial Pacific before and after the Pacific climate shift of the 1970s. Geophys. Res. Lett., 31, L03203, doi:10.1029/ 2003GL018829.

Moore, A. M., and R. Kleeman, 1999: Stochastic forcing of ENSO by the intraseasonal oscillation. J. Climate, 12, 1199-1220.

Reynolds, R. W., and T. M. Smith, 1994: Improved global sea surface temperature analyses using optimum interpolation. J. Climate, 7, 929-948.

Roulston, M. S., and J. D. Neelin, 2000: The response of an ENSO model to climate noise, weather noise, and intraseasonal forcing. Geophys. Res. Lett., 27, 3723-3726.

Roundy, P. E., and G. N. Kiladis, 2006: Observed relationship between oceanic Kelvin waves and atmospheric forcing. J. Climate, 19, 5253-5272.

Shinoda, T., and H. H. Hendon, 2002: Rectified wind forcing and latent heat flux produced by the Madden-Julian oscillation. J. Climate, 15, 3500-3507.

Smith, R. D., J. K. Dukowicz, and R. C. Malone, 1992: Parallel ocean general circulation modeling. Physica D, 60, 38-61.

Taylor, K. E., 2001: Summarizing multiple aspects of model performance in a single diagram. J. Geophys. Res., 106, 7183 7192.

Teng, H. Y., and B. Wang, 2003: Interannual variations of the boreal summer intraseasonal oscillation in the Asian-Pacific region. J. Climate, 16, 3572-3584.

Uppala, S. M., and Coauthors, 2005: The ERA-40 reanalysis. Quart. J. Roy. Meteor. Soc., 131, 2961-3012.

Zavala-Garay, J., A. M. Moore, and R. Kleeman, 2004: Influence of stochastic forcing on ENSO prediction. J. Geophys. Res., 109, C11007, doi:10.1029/2004JC002406. C. Zhang, A. M. Moore, and R. Kleeman, 2005: The linear response of ENSO to the Madden-Julian oscillation. J. Climate, 18, 2441-2459. 